\title{
FORECASTING EURO AREA INFLATION USING SINGLE-EQUATION AND MULTIVARIATE VAR-MODELS
}

Dieter Gerdesmeier, Prof. Dr.

\author{
European Central Bank \\ Sonnemannstraße 20, 60314 Frankfurt am Main, Germany \\ Frankfurt School of Finance and Management \\ Adickesallee 32-34, 60322 Frankfurt am Main, Germany \\ e-mail: dieter.gerdesmeier@ecb.europa.eu
}

Barbara Roffia, Dr.

European Central Bank

Sonnemannstraße 20, 60314 Frankfurt am Main, Germany

e-mail: barbara.roffia@ecb.europa.eu

Hans-Eggert Reimers, Prof. Dr.

Hochschule Wismar

Wismar Business School

Postfach 1210, 23952 Wismar, Germany

e-mail:Hans-Eggert.Reimers@hs-wismar.de

\begin{abstract}
Forecasting inflation is of key relevance for central banks, not least because the objective of low and stable inflation is embodied in most central banks' mandates and the monetary policy transmission mechanism is well known to be subject to long and variable lags. To our best knowledge, central banks around the world use conditional as well as unconditional forecasts for such purposes. Turning to unconditional forecasts, these can be derived on the basis of structural and non-structural models. Among the latter, vector autoregressive (VAR)-models are among the most popular tools.

This study aims at assessing and deriving a set of unconditional forecasts for euro area inflation based on several specifications which take into account the information content of, inter alia, monetary and credit variables. The models are ordered and based on their in-sample performance and the "best" model is selected accordingly. The results indicate that the inclusion of money and credit variables in the information set improves the quality of the forecasts over a horizon of one to eight quarters. This supports the view that central banks should regularly monitor developments in money and credit.
\end{abstract}

Keywords: inflation forecasts, euro area, Bayesian VAR

JEL classification: E31, E47, C11 


\section{Introduction}

Most central banks have been assigned a mandate of preserving price stability. In light of the well-known long and variable lags dominating the process of the monetary policy transmission process, it is thus essential to predict the process of price developments as accurate as possible in order to decide about the adequate stance of monetary policy.

Against this background, the empirical literature has made use of a variety of empirical tools, ranging from simple univariate time series models to large structural macroeconomic models and/or various types of vector-autoregressive models. While large structural models in essence rely on hypothesized theoretical relations, they were criticized by Lucas (1976) as being highly inappropriate for policy analysis. In addition, it was argued that the embedded restrictions used in the context of the estimation process could often be regarded as "incredible" (Sims, 1980).

Ever since their introduction into the literature by Sims, VAR models have become very popular forecasting tools due to their rather simple set-up as well as due to some dissatisfaction with the forecasting performance of large-scale structural models. Besides, VAR models have proven to be quite powerful in short-term forecasting.

This study aims at reviewing various types of single equations and VAR models and assessing them in the context of deriving unconditional forecasts for the euro area inflation rate. In line with the ECB's mandate, this analysis focuses on aggregate data for the euro area. After estimating several univariate and multivariate models and carrying out inflation forecasts over different horizons (one, four and eight quarters ahead), the Diebold-Mariano test is applied and the "best" model is selected. While the univariate auto-ARIMA approach outperforms naïve ARIMA-models noticeably, (B)VAR models perform better, in particular when monetary and credit variables are included in the specification, This result stresses the importance for central banks to include developments in money and credit in their information set in order to obtain more reliable inflation forecasts.

\section{Literature review and data description}

There is a vast amount of literature on inflation forecasts for which any attempt to summarize it would not do justice to the existing studies. In light of this, just a few of them are herewith cited, which provide the basis and/or starting point of our exercise. To begin with, Forni et al. (2003) make use of a large data set for the main countries of the euro area. The basic approach of the authors consists in simulating out-of-sample predictions for euro-area industrial 
production and the harmonized inflation index in order to assess the importance of financial variables for the forecast process. When comparing the results achieved on the basis of the large data panel with those achieved by means of a univariate autoregressive model, the authors find that multivariate methods outperform univariate methods for forecasting inflation at horizons of up to one year and that financial variables prove helpful in forecasting inflation.

More recently, Monteforte and Moretti (2008) made a similar attempt to forecast inflation on the basis of a large set of variables. Different from earlier approaches, however, the authors make use of a mixed-frequency model (the Mixed Data Sampling Regression Models), which allows for the simultaneous use of monthly variables and daily data (which, in principle, should contain more timely information about changes in inflation expectations). The results show that forecasts emerging from this type of model outperform those of standard benchmark models which are based only on monthly variables. In line with this, the use of daily financial variables leads to an improvement in inflation forecasts.

Ciccarelli and Mojon (2010) approach the same issue from a slightly different perspective. Their approach basically rests on the idea of deriving national inflation equations in a first step that are enhanced by global factors in a second step. The authors then test for the importance of such "common factors" using data for 22 industrialized OECD countries. It can then be shown that inflation in industrialized countries turns out to be largely a global phenomenon.

By contrast, Mikolajun and Lodge (2016) express some scepticism about the importance of global factors for forecasting inflation. Based on their results, they conclude that commodity prices are sufficient for capturing the global dimension and other global factors do not provide additional information.

Another approach has been used recently by Berg and Henzel (2014), who rely on a Bayesian vector auto regression to forecast the euro area HICP inflation rate over one and four quarters ahead. In this respect, their work builds on the work of Giannone, Lenza and Primiceri (2012) who generalize the proposal of Forni et al. (2003). Besides a forecast comparison, the authors also apply calibration tests to assess density forecasts. Their preferred model a BFAVAR - uses 22 variables and dominates simple random walk models.

\section{ARIMA models}

The first type of model consists in specifying inflation by means of a pure time series approach. More generally, the expression "time series" analysis is often used as a synonym for the so-called "Box-Jenkins approach", a technique that was developed in the 1970s. In essence, 
this technique completely abstracts from the traditional approach of using explanatory variables suggested by economic theory to explain and forecast developments, while focusing solely on the past behaviour of the variable under investigation and current and past errors. In a broader sense, this approach can be interpreted as a more sophisticated approach of extrapolation and, following Kennedy (1996), could take the form:

$$
Y_{t}=\alpha+\beta_{1} \times Y_{t-1}+\ldots+\beta_{p} \times Y_{t-p}+\varepsilon+\theta_{1} \times \varepsilon_{t-1}+\ldots \theta_{q} \times \varepsilon_{t-q}
$$

where $Y$ denotes the (quarter-on-quarter) rate of change in the harmonised index of consumer prices, the $\beta$ 's and the $\theta$ 's are the unknown parameters and $\varepsilon$ is a random error. In their seminal work, Box and Jenkins (1970) use $p$, which determines the autoregressive dimension of the model, and $q$, which represents the moving average dimension of the model. Information criteria are applied for the selection of lags. At the same time, it is intuitively clear that such a "backward-looking" approach must encounter difficulties when it comes to turning points in the cycle.

In our analysis, we make use of a traditional ARIMA model and, in addition, apply an "Error, Trend, Season" (ETS) exponential smoothing model (auto-ARIMA), which is based on an automatic selection process in order to arrive at the best specification for each (see Hyndman, Athanasopoulos, 2013).

\section{VAR and BVAR models}

Vector autoregressive models ("VAR models") are a particularly suitable tool for estimating and forecasting. Sims (1980) first introduced such models into the literature in the 1980s and, since then, the VAR methodology has become a very popular and well-respected concept in the area of time series modelling. In his seminal contribution, Sims criticized that traditional macro-econometric models would need to impose too many implausible restrictions on simultaneous equation models in order to identify them. These restrictions were often highly incredible because in a general equilibrium analysis, all variables can be expected to affect all other variables. By contrast, VAR models treat all variables as endogenous. The general representation of such a model reads as follows:

$$
Y_{t}=A+B(L) Y_{t-1}+\varepsilon
$$

where $Y_{t}$ is a vector of several variables measured over the same sample period $(t=1, \ldots, T)$, $A$ a vector of absolute terms, $B$ a matrix of autoregressive coefficients and $\varepsilon$ a vector of error 
terms. Since all the variables in this system have exactly the same set of explanatory variables, the system can be estimated, equation by equation, by use of Ordinary Least Squares (see Zellner, 1962). While VAR-models are undoubtedly very elegant and powerful systems, their specification and estimation gives rise to at least two kinds of problems.

One problem relates to the use of exogenous variables. While one of the original ideas behind VAR analysis was to treat every variable as endogenous, there are cases in which such an assumption is not warranted. For instance, in the case of small open economies, it may be necessary to include some exogenous variables.

A second problem relates to the large number of parameters: should a system of order $q$ include $p$ endogenous variables, the number of parameters to be estimated equals $p^{2} \times q$ plus additional parameters in case of the presence of deterministic trends. Therefore, in general, the number of variables that can be included in a VAR is limited. ${ }^{1}$

When approaching the first problem, a simple modification of the standard specification could solve the issue, for instance:

$$
Y_{t}=A+B(L) Y_{t-1}+C(L) X_{t}+\varepsilon
$$

The vector $X$ is included to allow for the contemporaneous influence of exogenous variables such as, for instance, the exchange rate, oil prices, or a time trend. In line with these considerations, a standard three-variable VAR would, for instance, read as follows:

$$
\begin{aligned}
& Y_{t}^{\prime}=\left[\begin{array}{lll}
\pi_{t} & y r_{t} & s_{t}
\end{array}\right] \\
& X_{t}{ }^{\prime}=\left[\text { exchrate }_{t} \text { oilprices }_{t}\right]
\end{aligned}
$$

where $\pi$ stands for the inflation rate, while $y r$ and $s$ denote real GDP and the short-term interest rate, respectively. Moreover, the (real effective) exchange rate (exchrate) and oil prices (opilprices) have been added to the basic model as exogenous variables, while implicitly assuming that there is no feedback from the former variables to the exogenous ones. Such models are often called "VAR-X models" in the literature.

The second shortcoming of traditional VARs is their rather generous parameterization of the model. Besides other solutions, the estimation of so-called "Bayesian VARs" ("BVARs") provides an effective way of dealing with the problem of an over-parameterization. By specifying plausible a-priori information in the form of so-called "prior distributions" on the

\footnotetext{
1 In response, several statistical criteria have been developed in order to determine the number of lags (see, for instance, Akaike, 1973).
} 
VAR coefficients and the variance-covariance matrix, the latter methods offer an efficient way of shrinking the parameter space.

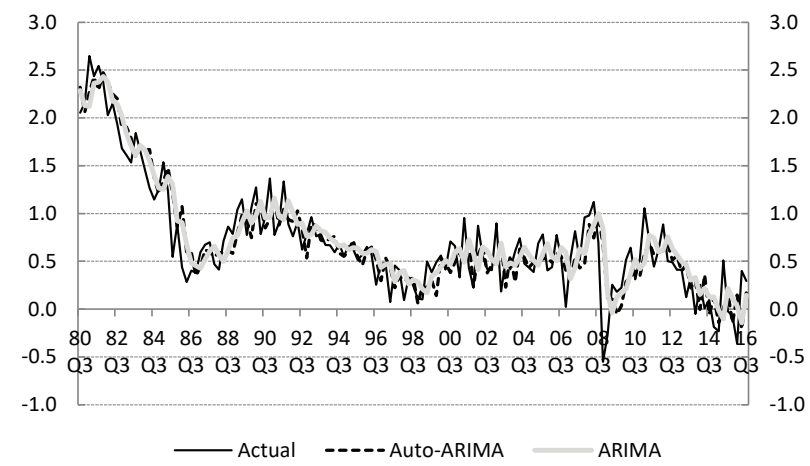

Sample: 1980 Q3 to 2016 Q3.

Figure 1. Euro area inflation forecasts based on univariate models Source: ECB, own estimates.

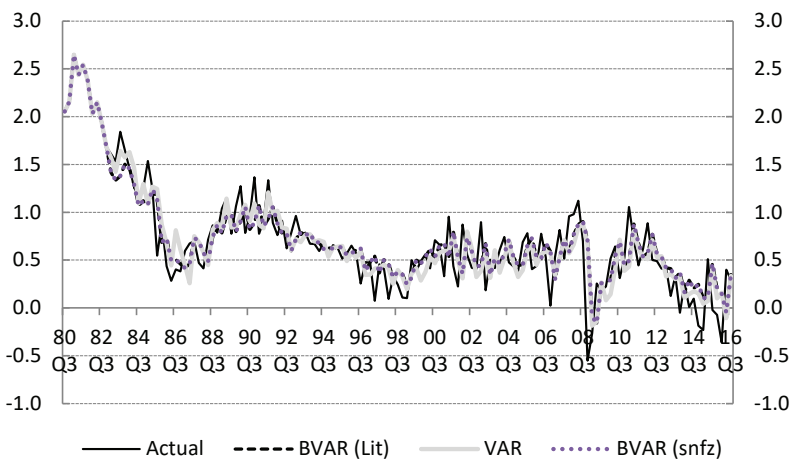

Note: "Lit" denotes Litterman's priors while "S\&Z" stands for Sims and Zha priors.

Sample: see Figure 1

Figure 2. Euro area inflation forecasts based on (B)VAR models

Source: ECB, own estimates.

For instance, the so-called "Minnesota prior" involves setting the elements of the parameter-prior and the covariance-prior in a way that is quite realistic from an empirical perspective as it tends to reflect the random-walk behaviour that generally characterises the level behaviour of many macro-economic variables. Moreover, the Minnesota prior assumes the 
prior variance-covariance matrix to be diagonal, implying that there is no relationship among the coefficients of the various VAR equations. In addition, the diagonal elements of the prior variance-covariance matrix are such that the most recent lags of a variable are expected to contain more information about the variable's current value than earlier lags. Finally, the lags of other variables are assumed to have less information than the lags of their own variables. By contrast, the Sims and Zha (1998) proposal relies on a normal flat prior distribution. The results emerging from the use of this prior distribution are employed as a cross-check with the results based on the Minnesota prior. $^{2}$

The two figures above show the results of the unconditional forecasts based on the univariate models presented in section 3 and the (B)VARs illustrated in this section (see Figure 1 and Figure 2). From the charts two messages emerge. First, the univariate models seem to track actual developments quite well. If anything, the ARIMA seems to show a smoother pattern than the auto-ARIMA model. Second, when comparing the simple VAR-model with its Bayesian equivalents, the BVARs do not show substantial improvements vis-à-vis with the simple VARs. This notwithstanding, the Bayesian variants seem to track actual developments more closely.

\section{A VECM approach}

Finally, another set of models explicitly distinguishes between the short-run and long-run properties inherent in the data. This can be done in various steps. In the first step, the maximum likelihood procedure by Johansen (1990) can be used to determine the number of cointegration vectors and to distinguish between the long-run relationships and the short-run dynamics. In order to identify the long-run relationships, tests on weak exogeneity can be carried out in the second step.

The starting point of this methodology is a vector error correction model of the following type:

$$
\Delta y_{t}=\Pi y_{t-1}+\sum_{i=1}^{k-1} \Gamma_{i} \Delta y_{t-i}+B x_{t}+\mu+\varepsilon_{t}
$$

where $y_{t}$ is a $(n x 1)$ vector of the several variables, $x_{t}$ a $(m x 1)$ vector of exogenous variables, $\mu \mathrm{a}(n x 1)$ vector of constants, $\Gamma_{i}$ represents $(n x n)$ matrices of short-run coefficients, $\Pi$ is a ( $\left.n x n\right)$ coefficient matrix, $B$ a matrix of the exogenous parameters, $k$ the lag order of the VAR and $\varepsilon_{t}$

\footnotetext{
2 Another key advantage of the Minnesota prior is that the resulting posterior of the parameter vector has a normal distribution. This allows us to calculate the posterior mean of the estimates without having to resort to different sampling techniques (e.g. Gibbs-sampling), which also reduces computational time substantially. See Litterman (1986) for more details on the Litterman prior. See also Sims and Zha (1998) for a more elaborated treatment of the Sims-Zha prior.
} 
is a vector of white noise residuals. Granger's (1987) representation theorem asserts that, if the coefficient matrix $\Pi$ has the reduced rank $r<n$, there exist ( $n x r$ ) matrices $\alpha$ (the loading coefficients or adjustment parameters) and $\beta$ (the cointegrating vectors), each with rank $r$ (the number of cointegration relations or the cointegrating rank), such that $\Pi=\alpha \beta^{\prime}$ and $\beta^{\prime} y_{t}$ is stationary (see Engle, Granger, 1987). It has been shown in the literature that VAR-models that embody cointegrating relations produce better forecasts over longer horizons than traditional unrestricted VARs (see De Mello, 2009).

The Johansen procedure provides evidence in favour of just one long-run cointegrating vector, whereby all coefficients in this equation carry of the (theoretically) expected sign and prove to be individually significant. More precisely, the procedure results in the identification of a statistically significant long-run relationship, in which the euro area HICP can be expressed as a function of real GDP and the 3-month money market rate (with the real effective exchange rate of the euro and oil prices being exogenous variables).

\section{A FAVAR approach}

There are alternative ways of dealing with the problems of high dimensionality and overparameterization of the model. The so-called "factor-augmented" VAR models ("FAVAR") rely on a principal component analysis in order to shrink the parameter space (by identifying common factors from a set of variables). When extending the reduced-form VAR model with the factor structure, the framework can be expressed as follows (see Stock, Watson, 2005): ${ }^{3}$

$$
\left[\begin{array}{c}
Y_{t} \\
F_{t}
\end{array}\right]=f_{1}(L)\left[\begin{array}{c}
Y_{t-1} \\
F_{t-1}
\end{array}\right]+\ldots+f_{q}(L)\left[\begin{array}{c}
Y_{t-q} \\
F_{t-q}
\end{array}\right]+\varepsilon_{t}
$$

where $F$ is $N x 1$ vector of factors and $L$ are the polynomial lags. It is important to note that this equation cannot directly be estimated, because the factors are unobservable. However, the information from a variety of economic time series can be used and is contained in the information matrix $(\Gamma)$, which takes the following form:

$$
\Gamma_{t}=\Lambda^{f} F_{t}+\Lambda^{y} Y_{t}+\varepsilon_{t}
$$

where $\Gamma$ is a $P x 1$ matrix, $\Lambda^{f}$ represents a $P x N$ matrix of factor loadings, $\Lambda^{y}$ denotes a $P x M$ matrix and $\varepsilon$ stands for a Px1 matrix of error terms. Following Stock and Watson (2005), equation (8) is often labelled as a "dynamic factor model" and can be estimated by using a two-

\footnotetext{
3 See Bernanke et al. (2005).
} 
step estimation procedure. In the first step, a principal component analysis is used to construct a factor that captures the largest common variation in a set of variables (in our specific case, the real effective exchange rate, long-term interest rates and oil prices). As a second step, once this factor has been constructed by using a principal component analysis, the FAVAR model can be estimated by means of the standard VAR methods.

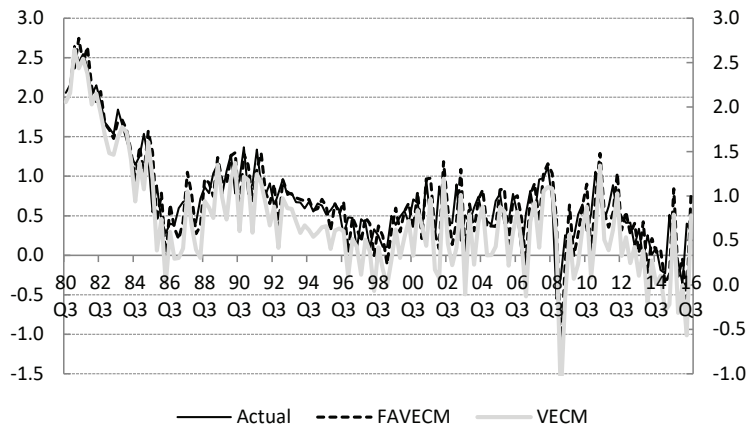

Sample: see Figure 1.

Figure 3. Euro area inflation forecasts based on (FA)VECM models

Source: ECB, own estimates.

Similarly to the results emerging from the BVAR-models, the FAVEC-model seems to track actual developments better than the corresponding (classical) simple specification (see Figure 3).

\section{Forecast Evaluation}

There are alternative ways of dealing with the problems of high dimensionality and various measures have been put forward in the literature in order to evaluate the forecast quality. Among them are the Mean Absolute Error (MAE), the Mean Absolute Percentage Error (MAPE), the Root Mean Square Error (RMSE) and Theil's U. As a rule, the lower the numbers, the better the quality of the forecast.

In this study, we evaluate the forecasting performance of the different models for the insample period. As regards the in-sample period, we derive the RMSE and Theil's U, which are defined as follows:

$$
\mathrm{RMSE}=\sqrt{\sum_{t=T+1}^{T+h}\left(\hat{y}_{t}-y_{t}\right)^{2} / h}
$$


and

$$
\mathrm{U}=\frac{\sqrt{\sum_{t=T+1}^{T+h}\left(\hat{y}_{t}-y_{t}\right)^{2} / h}}{\sqrt{\sum_{t=T+1}^{T+h}\left(\hat{y}_{t}\right)^{2} / h}+\sqrt{\sum_{t=T+1}^{T+h}\left(y_{t}\right)^{2} / h}}
$$

where $y_{t}$ represents the actual value of the dependent variable, while $\hat{y}_{t}$ represents the forecasted (one-step ahead) number. We, thereafter, derive the ratio of the forecast RMSE of each model with respect to the forecast RMSE of the other models: a number less than one indicates that the model in the numerator performs better (i.e. produces a lower MSE of the forecast) than the model in the denominator. In order to conclude whether the better performance is of statistical significance, we test it using the Diebold-Mariano Test:

$$
\mathrm{S}=\frac{\bar{d}}{s_{d}}
$$

where

$$
d=L_{1}-L_{2}
$$

and $L$ is either the squared or absolute difference between the forecast and the actual, i.e.:

$$
L_{i}=\left(\hat{y}_{i}-y_{i}\right)^{2}
$$

where $\overline{\mathrm{d}}$ and $s_{d}$ are the mean and sample standard deviation of $d$. Following Harvey, Leybourne, and Newbold (1998), we calculate the standard deviation using a small-sample bias corrected variance calculation. The test-statistic follows a Student's t-distribution with $T-1$ degrees of freedom. The ratios of the RMSE, the results from the Diebold-Mariano tests and the Theils-U are shown in tables $1-3$.

Table 1. Ratios of RMSEs - 1-step ahead

\begin{tabular}{|l|c|c|c|c|c|c|c|}
\cline { 2 - 8 } \multicolumn{1}{c|}{} & ARIMA & $\begin{array}{c}\text { Auto- } \\
\text { ARIMA }\end{array}$ & VAR & BVAR (Lit) & $\begin{array}{c}\text { BVAR } \\
\text { (S\&Z) }\end{array}$ & VECM & FAVECM \\
\hline ARIMA & - & 1.155 & 1.146 & 1.111 & 1.111 & 0.844 & 0.856 \\
\hline Auto-ARIMA & 0.866 & - & 0.992 & 0.962 & 0.962 & 0.730 & 0.741 \\
\hline VAR & 0.872 & 1.008 & - & 0.969 & 0.970 & 0.736 & 0.747 \\
\hline BVAR (Lit) & 0.900 & 1.040 & 1.032 & - & 1.000 & 0.759 & 0.770 \\
\hline BVAR (S\&Z) & 0.900 & 1.040 & 1.031 & 1.000 & - & 0.759 & 0.770 \\
\hline VECM & 1.186 & 1.370 & 1.359 & 1.317 & 1.318 & - & 1.015 \\
\hline FAVECM & 1.168 & 1.350 & 1.339 & 1.298 & 1.298 & 0.986 & - \\
\hline
\end{tabular}

Source: ECB, own estimates. 
Looking at the results, it is striking that the Auto-ARIMA procedure outperforms basically all other models in one-step ahead forecasting. The same holds for the simple VAR and BVAR models compared with the (FA)VEC models. The relatively worst performance can be attributed to the simple ARIMA and the (FA)VEC models. While in the former case, this might be due to a poor performance in catching the turning points, the latter could be attributed to the fact that the additional economic structure might only come to the fore over longer horizons. However, when looking at the Diebold-Mariano tests (Table 2), it seems that the outperformance of the Auto-ARIMA model vis-à-vis the (B)VARs is not statistically significant.

As a rule, the values for Theil's inequality $U$ lie between zero and one and a lower value of $U$ indicates a better fit of the model. In line with this, all models under consideration seem to have a reasonable fit. Perhaps not surprisingly, the auto-ARIMA shows the best fit when it comes to one-step ahead forecasting.

Table 2. Diebold-Mariano tests - 1-step ahead

\begin{tabular}{|l|c|c|c|c|c|c|c|}
\cline { 2 - 8 } \multicolumn{1}{c|}{} & ARIMA & $\begin{array}{c}\text { Auto- } \\
\text { ARIMA }\end{array}$ & VAR & BVAR (Lit) & $\begin{array}{c}\text { BVAR } \\
(\text { S\&Z) }\end{array}$ & VECM & FAVECM \\
\hline ARIMA & - & 0.064 & 0.106 & 0.163 & 0.162 & 0.195 & 0.002 \\
\hline Auto-ARIMA & 0.064 & - & 0.547 & 0.936 & 0.941 & 0.000 & 0.000 \\
\hline VAR & 0.106 & 0.547 & - & 0.325 & 0.327 & 0.000 & 0.000 \\
\hline BVAR (Lit) & 0.163 & 0.936 & 0.325 & - & 0.044 & 0.000 & 0.000 \\
\hline BVAR (S\&Z) & 0.162 & 0.941 & 0.327 & 0.044 & - & 0.000 & 0.000 \\
\hline VECM & 0.195 & 0.000 & 0.000 & 0.000 & 0.000 & - & 0.789 \\
\hline FAVECM & 0.002 & 0.000 & 0.000 & 0.000 & 0.000 & 0.789 & - \\
\hline
\end{tabular}

Note: $p$-values are shown in the table.

Source: ECB, own estimates.

Table 3. Theils-U - 1-step ahead

\begin{tabular}{|l|l|}
\hline ARIMA & 0.163 \\
\hline Auto-ARIMA & 0.143 \\
\hline VAR & 0.185 \\
\hline BVAR (Litterman) & 0.192 \\
\hline BVAR (Sims \& Zha) & 0.192 \\
\hline VECM & 0.240 \\
\hline FAVECM & 0.237 \\
\hline
\end{tabular}

Source: ECB, own estimates. 


\section{A model extension}

In this section, we extend the basic model by adding three key economic variables to the information set. Our choice is guided by the following considerations: To begin with, there is widespread agreement in the economic literature that money and credit developments constitute key variables in the process of monetary policy transmission. More particularly, a large consensus exists regarding both the direction and the dimension of the effect of an increase in the monetary aggregate on price developments (see Lucas, 1996). Second, credit cannot only be seen as a major counterpart of monetary developments, when evaluated though the lens of the consolidated MFI balance sheet, but it also plays a separate role in the context of the financing aspects of investment (see, among others, Friedman 1991). Finally, the yield spread has often been shown to have significant forecasting abilities for future economic developments (see Estrella, Hardouvelis, 1991).

Table 4. Ratios of RMSEs of auto-ARIMA vis-a-vis the other models - 1, 4 and 8-step ahead

\begin{tabular}{|c|c|c|c|}
\hline & 1-step & 4-step & 8 -step \\
\hline $\begin{array}{c}\text { (1) } \\
\text { Model }\end{array}$ & (2) & $(3$ & (4) \\
\hline Ygap (VAR) & 0.802 & 1.097 & 1.090 \\
\hline Ygap, HP (VAR) & 0.784 & 1.048 & 1.018 \\
\hline Ygap, HP, SP (VAR) & 0.767 & 1.045 & 1.008 \\
\hline Ygap. HP, SP, LP (VAR) & 0.766 & 1.024 & 0.929 \\
\hline Ygap, HP, SP, LP, M3 (VAR) & 0.746 & 1.019 & 0.906 \\
\hline Ygap, HP, SP, LP, M3, spread (VAR) & 0.742 & 1.015 & 0.903 \\
\hline Ygap (BVAR) & 0.812 & 1.101 & 1.103 \\
\hline Ygap, HP (BVAR) & 0.799 & 1.047 & 1.033 \\
\hline Ygap, HP, SP (BVAR) & 0.793 & 1.047 & 1.028 \\
\hline Ygap, HP, SP, LP (BVAR) & 0.790 & 1.028 & 0.974 \\
\hline Ygap, HP, SP, LP, M3 (BVAR) & 0.766 & 1.030 & 0.957 \\
\hline Ygap, HP, SP, LP, M3, spread (BVAR) & 0.765 & 1.023 & 0.952 \\
\hline
\end{tabular}

Note: Ygap - output gap, HP - house prices, SP - stock prices, LP - loans to the private sector, spread - the interest rate spread.

Sources: ECB, own estimates.

In Table 4 we present the ratios of the RMSE of the auto-ARIMA model vis-á -vis the RMSE of the (B)VAR models which include step-by-step additional variables, starting from the output gap (whereby potential output is approximated by use of a Hodrick-Prescott filter) and proceeding with the stock and house prices as well as M3, loans to the private sector and the yield curve (see column 2). The results show that - quite surprisingly - by far the best specifications 
for forecasting inflation when carrying out one-step ahead forecasts are represented by the models which also take into account the information from money and loans to the private sector (and the spread).

Table 5. Diebold-Mariano of the specification including Ygap, SP, HP, LP and M3 vis-a-vis the other models $-1,4$ and 8 -step ahead

\begin{tabular}{|l|c|c|c|}
\cline { 2 - 4 } \multicolumn{1}{c|}{} & 1-step & 4-step & 8-step \\
\hline Model & $(2)$ & $(3)$ & $(4)$ \\
\hline Auto-ARMA & & & 0.031 \\
\hline Ygap (VAR) & 0.005 & 0.639 & 0.001 \\
\hline Ygap, HP (VAR) & 0.015 & 0.003 & 0.005 \\
\hline Ygap, HP, SP (VAR) & 0.024 & 0.098 & 0.002 \\
\hline Ygap. HP, SP, LP (VAR) & 0.075 & 0.096 & 0.097 \\
\hline Ygap, HP, SP, LP, M3, spread (VAR) & 0.043 & 0.483 & 0.718 \\
\hline Ygap (BVAR) & 0.586 & 0.564 & 0.000 \\
\hline Ygap, HP (BVAR) & 0.011 & 0.003 & 0.019 \\
\hline Ygap, HP, SP (BVAR) & 0.016 & 0.248 & 0.014 \\
\hline Ygap, HP, SP, LP (BVAR) & 0.023 & 0.254 & 0.040 \\
\hline Ygap, HP, SP, LP, M3 (BVAR) & 0.028 & 0.553 & 0.099 \\
\hline Ygap, HP, SP, LP, M3, spread (BVAR) & 0.205 & 0.460 & 0.113 \\
\hline
\end{tabular}

Notes: $p$-values are shown for the Diebold-Mariano test. See also Table 4.

Sources: ECB, own estimates.

When evaluating the significance of the ratios by means of the Diebold-Mariano test (column 2 in Table 5), it turns out that the additional inclusion of the spread does not marginally improve the results, while the inclusion of the money and credit variables add significantly to the forecasting performance of the model. Finally, these results turn out to be independent on whether a VAR or BVAR model is used.

In the next step, we evaluate the previous results over additional forecast horizons (i.e. 4 and 8-step ahead, which seems to be common in the world of central banks). When taking a closer look at the four-quarter horizon (column 3, Table 4), on the basis of the ratios of RMSEs, the Auto-ARIMA procedure seems to perform slightly better, followed by simple VAR and BVAR models. However, as illustrated by the Diebold-Mariano test in more detail (column 3, Table 5), the differences between the Auto-ARIMA procedure and the VAR-model selected at 4-step ahead horizon is not statistically different. Similar results hold for the eight-quarter 
horizon (columns 4 in Table 5). This indicates that, overall, (B)VAR models that also include monetary and credit developments perform better in all of the considered horizons. ${ }^{4}$

\section{Overall assessment and conclusions}

Forecasting inflation is of key relevance for central banks, not least because the objective of low and stable inflation is embodied in most central banks' mandates and the monetary policy transmission mechanism is well known to be subject to long and variable lags. The purpose of this study has been to review and assess the performance of several models in forecasting euro area inflation for a period of one quarter, four and eight quarters ahead. In order to evaluate the outcomes of the different in-sample forecasts, a comparison of the RMSEs is carried out together with the Diebold-Mariano test. The following conclusions can be drawn. First, when comparing simple ARIMA models with simple (B)VAR models containing real GDP and shortterm interest rates, the latter turn out to perform quite well. Second, when including in (B) VAR models also information stemming from monetary and credit developments, these models perform better in all of the considered horizons. Therefore, these results support the need of a continuous monitoring and interpretation of monetary variables in the practice of monetary policy, which is line with the two-pillar strategy of the ECB and, in particular, the monetary pillar.

Some extensions of this work could be considered, in particular a closer investigation of the stability properties of the combinations of forecasts of different approaches. In this respect, Hubrich and Skudelny (2016) present promising results for the euro area by using weights depending on the forecast errors of the alternative models.

\section{References}

Akaike, H. (1973). Information theory and an extension of the maximum likelihood principle. In: B.N. Petrov (ed.), Proceedings of the Second International Symposium on Information Theory Budapest (pp. 267-281). Akademiai Kiado.

Berg, T.O., Henzel, S. (2014). Point and density forecasts for the euro area using Bayesian VARs. CESifo Working Paper, No. 4711.

\footnotetext{
${ }^{4}$ For space constraints, the tables containing the ratio of RMSEs and the Diebold-Mariano tests at 4 and 8-step ahead for the basic specifications illustrated in Section 7 are not shown but are available from the authors upon request.
} 
Bernanke, B.S., Boivin, J., Eliasz, P. (2004). Measuring the effects of monetary policy: a FactorAugmented Vector Autoregressive (FAVAR) Approach. NBER Working Paper, No. 1022.

Box, G.P., Jenkins, G.M. (1970). Time Series Analysis: Forecasting and Control. San Francisco: Holden Day.

Ciccarelli, M., Mojon, B. (2010). Global inflation. Review of Economics and Statistics, 3 (92), $524-535$.

De Mello, M.M. (2009). The role of cointegration and the forecast accuracy of VAR models. CEF.UP Working Paper, No. 2009-01.

Diebold, F.X., Mariano, R.S. (1991). Comparing predictive accuracy: an asymptotic test. Discussion Paper, No. 52, Institute for Empirical Macroeconomics, Federal Reserve Bank of Minneapolis.

Diebold, F.X., Mariano, R.S. (1995). Comparing predictive accuracy. Journal of Business and Economic Statistics, 13, 253-263.

Doan, T., Litterman, R., Sims, C.A. (1984). Forecasting and conditional projection using realistic prior distributions. Econometric Reviews, 3, 1-100.

Engle, R.F., Granger, C.W.J. (1987). Co-integration and Error Correction: Representation, Estimation, and Testing. Econometrica, 55 (2), 251-276.

Estrella, A., Hardouvelis, G.A. (1991). The term structure as a predictor of real economic activity. The Journal of Finance, 2 (46), 555-576.

European Central Bank (2014). The Phillips Curve relationship in the euro area. Monthly Bulletin, July, Frankfurt am Main.

Forni, M., Hallin, M., Lippi, M., Reichlin, L. (2003). Do financial variables help forecasting inflation and real activity in the euro area? Journal of Monetary Economics, 6 (50), 1243 1255 .

Friedman, B.M. (1991). Targets and instruments of monetary policy. NBER Working Paper, No. 2668. Also published in B.M. Friedman, F.H. Hahn (eds.). Handbook of Monetary Economics, Vol. II. Amsterdam: Elsevier Science Publishers B.V.

Giannone, D., Lenza, M., Primiceri, G.E. (2012). Prior Selection for Vector Autoregressions. NBER Working Papers, No. 19467.

Harvey, D.L., Leybourne, S.J., Newbold, P. (1998). Tests for Forecast Encompassing. Journal of Business and Economic Statistics, 16, 254-259.

Hubrich, K., Skudelny, F. (2016). Forecast combination for euro area inflation - a cure in times of crisis. FEDS Working Paper, No. 2016-104.

Hyndman, R.J., Athanasopoulos, G. (2013). Forecasting: principles and practice. OTexts.org/ fpp.

Johansen, S. (1991). Estimation and Hypothesis Testing of Cointegration Vectors in Gaussian Vector Autoregressive Models. Econometrica, 6 (59), 1551-1580. 
Kennedy, P. (1996). A Guide to Econometrics. 3rd edition. Cambridge, Massachusetts: The MIT Press.

Litterman, R. (1986). Forecasting With Bayesian Vector Autoregressions - Five Years of Experience. Journal of Business and Economic Statistics, 4, 25-38.

Lucas, R.E. (1976). Econometric Policy Evaluation: A Critique. Carnegie-Rochester Conference Series on Public Policy, 1, 19-46.

Lucas, R.E. (1996). Nobel Lecture: monetary neutrality. Journal of Political Economy, 4 (104), 661-682.

Mikolajun, I., Lodge, D. (2016). Advanced economy inflation: the role of global factors. ECB Working Paper Series, No. 1948.

Monteforte, L., Moretti, G. (2008). Real time forecasts of inflation: the role of financial variables. Banca d'Italia, mimeo.

Sims, C.A. (1980). Macroeconomics and Reality. Econometrica, 1 (48), 1-48.

Sims, C.A., Zha, T. (1998). Bayesian Methods for Dynamic Multivariate Models. International Economic Review, 4 (39), 949-968.

Stock, J.H., Watson, M. (2005). Implications of Dynamic Factor Models for VAR analysis. NBER Working Paper, No. 11467.

Zellner, A. (1962). An Efficient Method of Estimating Seemingly Unrelated Regressions and Tests for Aggregation Bias. Journal of the American Statistical Association, 57, 348-368. 